\title{
Leitura, sentido e significação
}

\author{
Patrícia da Silva Valério \\ Universidade de Passo Fundo - UPF \\ Marlete Sandra Diedrich \\ Universidade de Passo Fundo - UPF
}

\begin{abstract}
Resumo
O texto que se apresenta tem por objetivo revisitar as discussões do Círculo de Bakhtin que se encontram no substrato de concepções que podem ser a origem dos estudos sobre enunciação. A partir das discussões sobre interação verbal, tema e significação na língua, pretende-se analisar os efeitos de sentido produzidos pela palavra em situação real de uso, o que é entendido neste artigo como condição imprescindível para o trabalho de ensino de língua a ser desenvolvido nas escolas de Educação Básica.
\end{abstract}

Palavras-chave: significação, interação verbal, sentido.

\begin{abstract}
The objective of this article is to revisit the discussions of The Bakhtin Circle which underlie the conceptions that may be said to mark the beginning of the studies of enunciation. Based on the discussions of verbal interaction, theme and meaning in language, the article aims to analyze how sense is created by words produced in situations of real use. This kind of analysis is understood to be an essential condition for the job of language teaching that is to be developed in Elementary Schools.
\end{abstract}

Key words: meaning, verbal interaction, sense.

\section{CONSIDERAÇÕES INICIAIS}

Dentre a diversidade de temas que unem os artigos aqui apresentados, escolhemos a temática ensino e linguagem. É necessário, portanto, explicitar a razão dessa escolha e a relação entre nosso estudo e tal temática.

Atuamos como professoras de língua portuguesa na educação básica e no ensino superior há algum tempo e preocupamo-nos com os baixos níveis de leitura, assim como com a falta de embasamento teórico no trabalho com textos em sala de aula. Assim sendo, defendemos a necessidade de qualificar o trabalho docente de modo a produzir melhores resultados no que diz respeito à melhoria da competência comunicativa dos alunos.

Estudando a obra de Mikhail Bakhtin (e dos demais integrantes do Círculo de Bakhtin), especialmente suas discussões sobre língua/ linguagem, encontramos algumas 
referências que, acreditamos, podem ser úteis no trabalho com textos em sala de aula. Assim, cremos que nosso estudo dialoga com a temática proposta.

$\mathrm{O}$ texto que apresentamos discute questões relacionadas à produção do sentido/ enunciação. Para tanto, pretende resgatar algumas reflexões de Bakhtin/ Voloshinov sobre linguagem e interação, tema e significação e gêneros discursivos para discutir a possibilidade de um trabalho de leitura na escola que dê conta da construção e do resgate do sentido em situação concreta de enunciação.

Há muito a ser estudado em Bakhtin, cujo pensamento produziu reflexões em diferentes áreas, como história, crítica literária, filosofia, psicologia, linguística, dentre outras. Precisamos fazer um recorte e, por isso, selecionamos apenas alguns textos do autor e seu Círculo por entender que a leitura de tais textos é fundamental para pensar no trabalho com o texto em sala de aula, numa perspectiva discursiva.

Não pretendemos levar o leitor à exaustão, trazendo à tona argumentos já conhecidos e amplamente debatidos academicamente. Nossa intenção é tão somente embasar teoricamente a análise que fizemos de um texto cujo gênero merece ser melhor explorado em sala de aula. Isso justifica o retorno ao mestre, de modo a valorizar sua contribuição na análise da palavra em situação concreta de uso para abrir, assim, a possibilidade de se pensar a prática pedagógica da leitura enquanto resgate dos sentidos construídos a cada cena enunciativa.

\section{LÍNGUA VIVA}

Entre as obras mais conhecidas de Bakhtin e seu Círculo - Marxismo e Filosofia da linguagem - encontra-se a discussão sobre - e consequente rejeição - as duas orientações do pensamento linguístico-filosófico da época, o objetivismo abstrato e o subjetivismo idealista. Bakhtin rejeita ambas as correntes de pensamento, pois defende que "a língua vive e evolui historicamente na comunicação verbal concreta, não no sistema linguístico abstrato das formas da língua nem no psiquismo individual dos falantes" (2010a:128). Essa visão de língua viva é muito importante quando se pensa em ensino de língua, como veremos adiante.

Para Bakhtin, a realidade fundamental da língua é a interação verbal, sendo o diálogo uma das suas mais importantes formas. O autor entende a palavra diálogo em sentido amplo, não apenas como comunicação em voz alta, mera troca verbal face a 
face, mas como qualquer comunicação verbal, falada ou escrita: "O discurso escrito é integrante de uma discussão ideológica em grande escala: responde a alguma coisa, refuta, confirma, antecipa as respostas e objeções potenciais, procura apoio" (2010a: 128).

O diálogo, como processo de fala em sentido amplo, é processo ininterrupto, sem começo e fim. Seus limites serão sempre os pontos de contato com as outras enunciações: "a enunciação realizada é como uma ilha emergindo de um oceano sem limites, o discurso interior. As dimensões/formas dessa ilha são determinadas pela situação da enunciação e por seu auditório" (Bakhtin, 2010a:129). Sendo assim, qualquer enunciação constitui apenas uma fração de uma corrente ininterrupta de comunicação.

Para Bakhtin, "não são palavras o que pronunciamos ou escutamos, mas verdades ou mentiras, coisas boas ou más, importantes ou triviais, agradáveis ou desagradáveis. A palavra está sempre carregada de um conteúdo ou de um sentido ideológico ou vivencial" (2010a:99).

Nas palavras de Faraco (2006), a enunciação de um signo, de acordo com o Círculo de Bakhtin, "é sempre também a enunciação de índices sociais de valor, isto é, a enunciação de um signo tem efeitos de sentido que decorrem da possibilidade de sua ancoragem em diferentes quadros semântico-axiológicos, em diferentes horizontes sociais de valores" (p. 53).

Outra discussão importante em Bakhtin é a significação, tanto que o assunto está implicitamente presente em vários capítulos ${ }^{1}$ da obra MFL, sendo o capítulo final da segunda parte da obra o qual se dedica mais explicitamente ao assunto, embora, conforme o autor, de modo breve e superficial, o que parece revelar um possível interesse em dar continuidade à reflexão em estudos posteriores.

Conforme Bakhtin (2010a), a significação corresponde a um estágio inferior da capacidade de significar e o tema, a um estágio superior. "A significação não quer dizer nada em si mesma, ela é apenas um potencial, uma possibilidade de significar no interior de um tema concreto" (p. 136). Investigar a significação de uma determinada palavra pode orientar-se para duas direções: ou evoluir para um estágio que o autor

\footnotetext{
${ }^{1}$ No capítulo 2 de MFL, quando aborda a formulação do conceito ideológico, e na segunda parte da obra, quando parte da discussão das duas orientações do pensamento filosófico-linguístico para formular as bases para fundamentar o que entende por significação.
} 
denomina superior, que seria a depreensão do tema, ou rebaixar-se a um nível inferior, da sistematização da língua ou a significação em si, o sentido dicionarizado.

$O$ tema da enunciação, tal qual a enunciação, é individual e não reiterável "é a expressão de uma situação histórica concreta que deu origem à enunciação" (2010a: $133)$.

Tema e significação são como duas faces de uma mesma moeda. Não há um sem o outro. Se o tema é determinado não apenas pelas formas linguísticas, mas também pelos elementos verbais da situação de comunicação, sendo, portanto, concreto, a significação corresponde aos elementos da enunciação reiteráveis e idênticos a cada vez que são repetidos. É composta "das significações de todas as palavras que fazem parte dela, das formas de suas relações morfológicas e sintáticas, da entoação interrogativa, etc" (2010a:134).

Essa relação entre a forma linguística e seu uso, é definida por Flores \& Teixeira (2005:51) como uma via de mão dupla, ou seja, "há um sentido dado pela estrutura (reiterável e sempre igual) e há outro sentido que é dado pela enunciação (sempre mutável e adaptável)".

O filósofo russo explica que o processo de compreensão da enunciação de outra pessoa ocorre quando há uma orientação em relação a essa enunciação, quando se encontra o local adequado no contexto correspondente. Dito de outro modo: "a cada palavra que estamos em processo de compreender, fazemos corresponder uma série de palavras nossas, formando uma réplica. Quanto mais numerosas e substanciais forem, mais profunda e real é a nossa compreensão" (Bakhtin, 2010a:137). Essa é a razão que o leva a defender a ideia de que a compreensão é uma forma de diálogo "compreender é opor à palavra do locutor uma contra palavra" (p. 137).

Bakhtin (2010a) afirma que toda enunciação é uma orientação apreciativa, por isso na enunciação viva há sempre um sentido e uma apreciação. Quando ocorre uma mudança de significação é porque houve uma espécie de reavaliação, isto é, "ou a palavra foi elevada a um nível superior ou rebaixada a um nível inferior” (p. 141).

O sentido na enunciação é inacabado: "a significação, elemento abstrato igual a si mesmo, é absorvida pelo tema e dilacerada por suas contradições vivas, para retornar enfim sob a forma de uma nova significação com uma estabilidade e uma identidade igualmente provisórias" (2010a:141).

Entender tema e significação é importante para trabalhar com o texto em sala de aula. Se o professor concebe o texto como uma unidade viva, enquanto significação, e 
não apenas enquanto tema, poderá realizar um trabalho textual que leve os alunos a se tornarem mais competentes comunicativamente.

A terceira discussão em Bakhtin que consideramos relevante para pensar o ensino da língua é sobre os gêneros do discurso. As pessoas empregam a língua por meio de enunciados (orais e escritos) que refletem as condições específicas e as finalidades através de dado conteúdo, estilo, por meio da seleção de recursos estilísticos, léxicos, sintáticos, mas, acima de tudo, por sua estrutura composicional. Assim, embora cada enunciado seja individual, "a utilização da língua se dá através de tipos relativamente estáveis de enunciados, os gêneros do discurso" (Bakhtin, 2010b:262).

Para entender a importância dos gêneros discursivos, é necessário ter clareza quanto à distinção entre oração e enunciado. Bakhtin (2010b:287) diz que "a oração é uma unidade da língua, mas é desprovida da capacidade de determinar imediata e ativamente a posição responsiva do falante. Já o enunciado, por ser uma unidade de comunicação discursiva" (p. 276) é prenhe de resposta. Exige, portanto, uma espécie de diálogo, de compreensão responsiva. A noção de enunciado é fundamental para compreender o papel dos gêneros do discurso nas sociedades.

Conforme Bakhtin, "a vontade discursiva do falante se realiza antes de tudo na escolha de um certo gênero do discurso" (2010b:282). Nós falamos e escrevemos somente através de gêneros discursivos e, mesmo que desconheçamos, teoricamente, sua estrutura, precisamos dominá-los na prática para podermos nos comunicar. Bakhtin explica, através de analogia, como se dá o domínio discursivo dos gêneros. Os gêneros, comparados às formas da língua - que são fixas - são mutáveis, plásticos. Eles não são criados pelo falante, mas dados a ele. A língua (a langue, de Saussure) está para o falante enquanto forma, à sua disposição, mas é através dos gêneros discursivos que adquire status de enunciado (parole). Desse modo, os gêneros do discurso são tão indispensáveis para a compreensão entre os falantes quanto as formas da língua. Bakhtin afirma que quanto maior for nosso domínio sobre os gêneros e mais livremente formos capazes de empregá-los, "mais competentemente realizaremos de forma livre nosso projeto de discurso" (2010b:285).

Os gêneros do discurso organizam o nosso discurso quase da mesma forma que organizam as formas gramaticais (sintáticas). Nós aprendemos a moldar o nosso discurso em formas de gênero e, quando ouvimos o discurso alheio, já adivinhamos o seu gênero pelas primeiras palavras, adivinhamos um determinado volume (isto é, uma extensão aproximada do conjunto do discurso), uma determinada construção composicional, prevemos o fim, isto é, desde o início temos a sensação do conjunto 
do discurso que em seguida apenas se diferencia no processo da fala (Bakhtin, 2010b:283).

É evidente que as formas do gênero são bem mais flexíveis e plásticas do que as formas da língua, esclarece o filósofo russo. Essa característica torna a diversidade de gêneros bastante ampla, pois eles atendem a diferentes funções, como situação, posição social, relações pessoais e de reciprocidade entre os interlocutores. Ao produtor do texto (oral e escrito) cabe escolher o gênero que melhor atenda à função comunicativa desejada, desde a comunicação mais formal e oficial às mais íntimas e familiares. É importante destacar que quanto mais elevado e formal for o gênero, mais estável será sua forma e, nesse caso, a individualidade do falante fica menos evidente, pois esta se dá na escolha do gênero e na entonação expressiva, a qual pode assumir aspecto mais seco ou mais respeitoso, mais frio ou caloroso, mais alegre, etc. (Bakhtin, 2010b:284). Parece que Bakhtin quer nos dizer que mesmo quando o locutor escolhe um gênero mais padronizado, portanto mais fechado estruturalmente, é possível perceber a vontade discursiva individual do falante, a qual se manifesta nessa escolha e no tom expressivo utilizado.

Uma distinção importante em Bakhtin que não deve ser desprezada pelo professor de língua materna é a distinção entre oração e enunciado. A oração, assim como a palavra, é uma unidade significativa da língua. Por isso, cada oração isolada é compreensível linguisticamente. Mas a oração não possui entonação expressiva ${ }^{2}$, pois essa condição só passa a existir no enunciado. A expressão da língua é característica e condição do enunciado. Enquanto unidade da língua, a oração não tem a capacidade de determinar imediata e ativamente a posição responsiva do falante. Somente depois de se tornar enunciado pleno, isto é, uma oração individual, proferida por alguém num determinado tempo/espaço, é que a oração adquire essa capacidade. O enunciado está "emoldurado e delimitado pela alternância dos sujeitos do discurso e reflete imediatamente a realidade (situação) extraverbal. Esse enunciado suscita resposta" (Bakhtin, 2010b:287).

O que distingue essencialmente a oração do enunciado é seu traço constitutivo de ser direcionado, endereçado a alguém. As unidades significativas da língua, as palavras, as orações são impessoais, isto é, estão à disposição de todos os falantes da língua

\footnotetext{
${ }^{2}$ Sobre entonação, vale a pena conferir o texto de Amorim (2012), para quem a entonação é muito importante para a discussão da concepção de linguagem bakhtiniana. A autora defende que a entonação é uma marca linguística de valor, responsável pela dimensão ética, muito presente na obra bakhtiniana.
} 
indistintamente, já o enunciado tem sempre um autor e um destinatário. "Todo enunciado sempre responde (no sentido amplo da palavra) de uma forma ou de outra aos enunciados dos outros que o antecederam" (p. 300).

Como se vê, os falantes têm à sua disposição não apenas as formas da língua como também suas possíveis combinações, os gêneros do discurso. Para compreender os textos, é necessário compreendê-los enquanto gêneros. Não basta apenas levar um gênero discursivo para a sala de aula e esperar que os alunos identifiquem o gênero ou o classifiquem. É fundamental que o professor, com base na concepção bakhtiniana de gênero, discuta com os alunos as condições de produção desse texto, seu produtor, seu interlocutor, as diferentes possibilidades de sentido que o texto permite.

\section{A PALAVRA EM USO}

A fim de explicitar a contribuição das reflexões bakhtinianas para o trabalho com o texto na escola, analisaremos a ocorrência da palavra paraíso em uma situação real de uso. $\mathrm{O}$ texto que traz a palavra em análise pertence ao gênero discursivo charge e foi veiculado no jornal Zero Hora, RS, em 07 de outubro de 2011. É de autoria de Marco Aurélio.

Não pretendemos fazer aplicação dos conceitos a fim de compreender o discurso em questão, mas queremos, amparados nos estudos do mestre russo, "deixar que os discursos revelem sua forma de produzir sentido, a partir de um ponto de vista dialógico, num embate" (Brait, 2010:24).

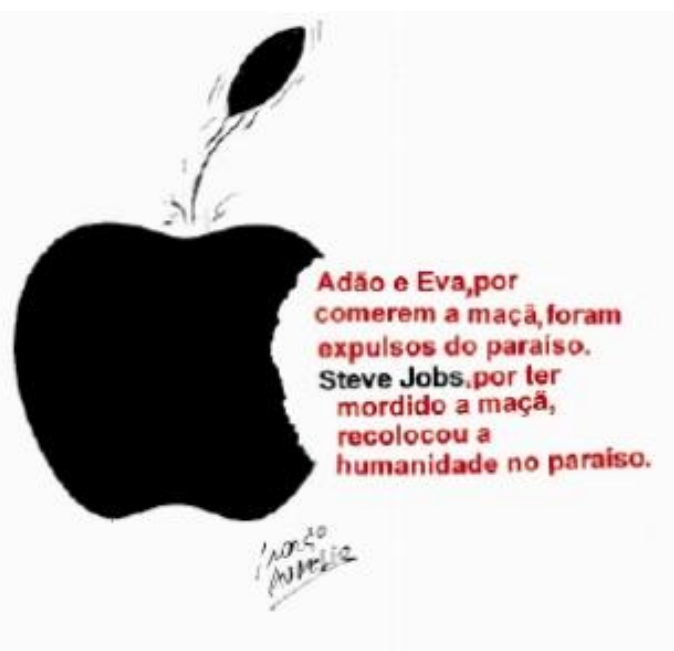


Trata-se de um texto misto, verbal e não-verbal. A figura maçã faz alusão ao texto bíblico (Gênesis), segundo o qual Adão e Eva teriam sido expulsos do paraíso por comerem o fruto proibido. Embora não se tenha registro no referido texto, tradicionalmente se convencionou associar tal fruto à maçã. Além desse sentido, observado o contexto, remete ao símbolo de uma conhecida empresa da área tecnológica. Destacamos, primeiramente, a palavra paraíso, reiterada no texto verbal, a fim de relacioná-la com os conceitos de tema e significação de Bakhtin. Em busca da significação, encontramos, no dicionário on-line aulete digital, as seguintes definições para este vocábulo:

Sem dúvida, para que ocorra a compreensão do sentido desse texto, faz-se necessária a identificação dos temas possíveis de serem depreendidos a partir da significação da palavra paraíso.

Como vimos, em Bakhtin a significação corresponde ao reiterável, àquilo que é idêntico, ao sistema, enquanto o tema é individual, não-reiterável.

Uma primeira significação, mais concreta no texto, pode ser identificada a partir do conhecimento de mundo do leitor, relacionando os elementos verbais Adão, Eva, maçã, paraíso com o elemento não-verbal maçã. Essa relação levará a depreensão do significado do vocábulo no dicionário, mais especificamente nas acepções 1 e 2 . A leitura desse primeiro período revela uma relação de causa/ efeito negativo.

O tema 1 revela a leitura de paraíso como sinônimo de Éden, no sentido bíblico do termo. Observa-se que, caso não haja a identificação do tema, apenas a identificação da significação do vocábulo paraíso será insuficiente para a construção do sentido desse texto.

Na sequência da leitura, ocorre uma substituição dos vocábulos Adão e Eva por um único vocábulo, Steve Jobs. Além disso, a locução verbal terem comido é substituída por ter mordido, ocorrendo, novamente, uma relação causa/ efeito positiva. 
Se no primeiro período (tema 1) ocorre a expulsão do paraíso, no segundo (tema 2) há uma recolocação no paraíso, cujo elemento desencadeador é a maçã (comida, no tema 1 ; mordida, no tema 2).

Caso o leitor não estabeleça a relação entre os elementos Steve Jobs e maçã (símbolo da empresa de computação reconhecida internacionalmente que leva o nome da fruta em inglês), não conseguirá chegar ao tema da enunciação.

O significado do termo paraíso, de que trata o segundo período do texto, não se encontra dicionarizado, precisa, portanto, ser construído pelo interlocutor no processo de interação com o texto.

Nessa segunda construção de tema (2), evidencia-se uma espécie de homenagem a um dos principais fundadores da empresa Apple, falecido na época de veiculação do texto. Como a empresa foi pioneira no ramo, o tema a ser construído a partir da leitura do segundo período é que Steve Jobs, ao morder a maçã, ou seja, ao criar a empresa Apple, ou melhor, os produtos que a empresa comercializa na área da informática, recolocou a humanidade no paraíso - em um sentido metafórico, evidentemente. O conforto que a tecnologia produzida pelos computadores com acesso à internet, telefones celulares, smartphones, etc, que permitem comunicação e acesso à informação instantânea fornece aos consumidores está associado ao conceito de felicidade.

Os dois períodos verbais do texto constroem relações de causa/ efeito negativa e positiva, através da relação entre os elementos maçã e paraíso, isto é, o sentido dos vocábulos atualiza-se no discurso através de uma evolução histórica. "Uma nova significação se descobre na antiga e através da antiga, mas a fim de entrar em contradição com ela e de reconstruí-la" (Bakhtin, 2010a:141).

De posse dessas relações de sentido acima expostas, propomos, na sequência, alguns pontos acerca da possibilidade de se explorarem tais relações num trabalho de leitura na sala de aula da Educação Básica. O conceito de leitura aqui explorado está intimamente relacionado à noção de significação, conforme proposta por Bakhtin, o que nos motiva a afirmar que um trabalho dessa natureza envolve investimentos por parte do professor mediador capazes de levar o educando leitor a tecer relações que extrapolam a superfície textual, movendo-o a buscar em outras enunciações informações necessárias para compor o todo de significado do discurso em foco. Sabemos que o educando leitor nem sempre tem consolidado o conhecimento de mundo necessário para resgatar tais informações. Por essa razão, o professor é visto aqui como mediador entre essas informações e o leitor em questão. Cremos que se trata da didatização do trabalho de 
leitura, o que, como sabemos por dados levantados em nossa experiência como professoras orientadoras de Estágio Supervisionado no curso de Letras, nem sempre acontece nas escolas. Infelizmente, ainda se compartilha, em muitas realidades de sala de aula, da ideia equivocada de que o trabalho com a leitura envolve apenas atenção por parte do educando leitor.

A didatização do trabalho de leitura, portanto, diz respeito a um conjunto de noções necessárias para o resgate do sentido pretendido no discurso a ser analisado. Para tanto, exige que o professor mediador organize sua prática em função dos seguintes aspectos:

a) Interação. A partir da noção de enunciado, é importante a concepção do outro no discurso. Não há enunciado sem o outro. O professor de língua materna deve estimular o aluno a observar a situação, isto é, o contexto em que o texto é produzido; a presença da bivocalidade ou do dialogismo, ou seja, a que o texto responde, ou o que rejeita, confirma, antecipa.

b) Tema/ significação. É importante que o aluno saiba que compreender, de fato, um texto é construir sentido. O sentido é único em cada enunciação, por isso apreendemos a estrutura da língua, para dominá-la ao ponto de reconhecermos os sentidos construídos a cada enunciação.

c) Gênero discursivo. Se, conforme Bakhtin, "a vontade discursiva do falante se realiza antes de tudo na escolha de um certo gênero do discurso e é através de gêneros que nos comunicamos" (2010b:282), é importante dominarmos a estrutura de diferentes gêneros para podermos melhor nos comunicar. Parece, portanto, que este é o papel da escola: preparar o aluno para ler e produzir textos de forma autônoma e competente.

\section{CONSIDERAÇÕES FINAIS}

As discussões de Bakhtin e seu Círculo sobre o objetivismo abstrato - recusado pelos autores que não concordam em conceber a língua como um sistema abstrato de normas rígidas e imutáveis - assim como sobre o subjetivismo idealista, que defende a construção da expressão como algo realizado no interior, são coerentes com a postura de pensadores que não se declaravam linguistas, mas filósofos. Para eles, "o centro de gravidade da língua não está na adequação à norma da forma em uso, mas na nova significação que essa forma adquire no contexto" (2010a:96). 
A leitura do texto de Marco Aurélio e a observação dos sentidos possíveis de depreensão do termo paraíso nesse contexto específico de uso evidenciam a relevância das reflexões bakhtinianas sobre tema e significação na língua.

Para os filósofos da linguagem, o sentido é construído a partir da identificação da significação, a qual, absorvida pelo tema e destruída por suas contradições vivas, pode retornar sob forma de uma nova significação, que terá sua estabilidade e sua identidade novamente em estado provisório. Esse fenômeno revela-se na construção do sentido do texto de Marco Aurélio, em especial no termo paraíso, que absorve o tema $1 \mathrm{e}$, em seguida, destitui-se da significação produzida para absorver o tema 2 e criar uma nova significação.

Esse é o caráter da enunciação, prenhe de sentido, prenhe do outro (leitor) que, em conjunção com o texto, dá-lhe vida, provisória, num ciclo interminável de construção de sentido.

Acreditamos que a contribuição de Bakhtin no que se refere ao estudo sobre linguagem, tema e significação na língua e gêneros textuais não pode ser desprezada pelos professores que atuam na Educação Básica, uma vez que as discussões sobre esses temas possibilitam a ancoragem de um trabalho produtivo com o texto em sala de aula.

\section{REFERÊNCIAS}

Amorim, M. (2012). Para uma filosofia do ato: "válido e inserido no contexto" In: Brait, B. (org.). Dialogismo e polifonia. São Paulo: Contexto.

Bakhtin, M. V. (2010a). Marxismo e filosofia da linguagem. São Paulo: Hucitec.

(2010b). Estética da criação verbal. São Paulo: Martins Fontes.

Brait, B. (2006). Análise e teoria do discurso. In: Brait, B. (org.). Bakhtin: outros conceitos-chave. São Paulo: Contexto.

Faraco, C. A. (2006). Linguagem e diálogo: as ideias linguísticas do Círculo de Bakhtin. 2. ed. São Paulo: Parábola Editorial.

São Paulo: Contexto. (2010). Autor e autoria. In: Brait, B. (org.). Bakhtin: conceitos-chave.

Flores, V.N. \& Teixeira, M. (2005). Introdução à linguística da enunciação. Contexto: São Paulo. 


\section{AS AUTORAS}

Patrícia da Silva Valério é graduada em Letras pela Universidade de Passo Fundo, mestre em Letras/ Estudos Linguísticos pela Universidade de Passo Fundo e doutoranda em Linguística Aplicada pela UNISINOS.

E-mail: patriciav@upf.br

Marlete Sandra Diedrich é graduada em Letras pela Universidade de Passo Fundo, mestre em Linguística pela Pontifícia Universidade Católica do Rio Grande do Sul e doutoranda em Letras pela UFRGS.

E-mail: marlete@upf.br 